\title{
Indexação Financeira e Comportamento Pró-Cíclico da Dívida Pública Mobiliária Federal Interna no Brasil
}

\section{Financial Indexation and Procyclical Behavior of Brazilian Public Debt}

Giuliano Contento de Oliveira* Carlos Eduardo Carvalho**

\begin{abstract}
Resumo: $\mathrm{O}$ artigo discute a relação entre indexação financeira (existência de títulos corrigidos pelos juros de curtíssimo prazo, com liquidez imediata) e comportamento pró-cíclico da dívida pública mobiliária federal interna (DPMFi) no Brasil, entendido como a sensibilidade da parcela da DPMFi indexada aos juros de curto prazo às mudanças efetivas e esperadas da taxa Selic, com particular atenção ao período posterior à instituição do regime de metas para a inflação. A partir de um Vector Error Correction Model (VECM), sustenta-se que a indexação de boa parte da dívida aos juros de curto prazo reduz a autonomia na gestão da dívida pública, uma vez que mudanças na taxa básica de juros ou de variáveis que sinalizem sua elevação, elevam a participação dos títulos públicos federais atrelados aos juros de curto prazo na DPMFi.
\end{abstract}

Palavras-chave: Dívida pública. Indexação financeira. Gestão da dívida pública.

Abstract: The paper discusses the relationship between financial indexation (existence of treasury bonds indexed to short-term interest rate, with high liquidity) and procyclical behavior of Brazilian public debt - the sensibility of indexed parcel of DPMFi to Selic to effective and expected changes of Selic, with particular attention to the period after the establishment of the inflation targeting system. Through a Vector Error Correction Model (VECM), it is argued that the indexation of much of the public debt to Selic decrease the autonomy in public debt management, because changes in the Selic, or variables that signalize its elevation, increase the participation of treasury bonds indexed to Selic.

Keywords: Public debt. Financial indexation. Public debt management.

JEL Classification: $\mathrm{H} 60 ; \mathrm{H} 63$.

\footnotetext{
* Professor do Instituto de Economia da Unicamp. Email: giulianoliveira@gmail.com

** Professor do Departamento de Economia e do Curso de Relações Internacionais da PUC/SP. Email: cecarv@uol.com.br
} 


\section{Introdução}

A indexação dos títulos públicos federais à taxa de juros de curtíssimo prazo $^{1}$ imprime uma dinâmica pró-cíclica à dívida pública mobiliária federal interna (DPMFi) no Brasil: quando sobem os juros, ou quando surgem indicadores de aumentos futuros da taxa de juros, cresce a parcela da DPMFi atrelada à taxa Selic, aumentando a própria DPMFi; quando os juros de curto prazo caem, ocorre movimento inverso. A indexação financeira da DPMFi, representada pelo total dos títulos públicos federais em mercado emitidos pelo Tesouro Nacional e pelo Banco Central atrelados à taxa Selic, ${ }^{2}$ minimiza os efeitos positivos ocasionados pela política de superávits fiscais primários sobre as condições de endividamento do setor público brasileiro. Dificulta-se, pois, a gestão ativa da dívida pública, aqui entendida como aquela capaz de minimizar os custos do financiamento do setor público e, ao mesmo tempo, potenciar o grau de eficiência da política monetária.

Se por um lado a indexação dos títulos públicos à taxa Selic viabilizou o financiamento do setor público mesmo sob contexto de elevado risco de aumento da taxa básica de juros, pois concorreu para eliminar o risco de perda de capital decorrente de elevações dos juros de curtíssimo prazo, por outro operou no sentido de onerar demasiadamente as contas públicas depois do Plano Real. A despeito da existência de outros condicionantes da trajetória crescente da dívida líquida do setor público no Brasil depois da estabilização monetária, como o reconhecimento de dívidas antigas e o impacto derivado das operações de esterilização monetária e do consequente déficit quasi-fiscal, ${ }^{3}$ uma análise retrospectiva cuidadosa mostra que a carga de juros correspondeu a um dos mais importantes condicionantes da elevação substantiva da dívida pública no Brasil no período aludido (CARVALHO, 2005; HERMANN, 2002; CARNEIRO, 2002).

Nesse sentido, o artigo tem o objetivo de analisar os impactos de variáveis macroeconômicas selecionadas (juros, inflação e câmbio) sobre a parcela da DPMFi indexada à taxa de juros de curto prazo no Brasil. Sustenta-se que a indexação de parcela relevante dos títulos públicos à taxa de juros de curto prazo impõe um comportamento pró-cíclico à DPMFi no Brasil.

1 Embora a taxa de juros ou a taxa de câmbio não sejam índices, justifica-se utilizar o termo indexação por se tratar de procedimento assemelhado, na forma e nos efeitos, à indexação de títulos e de taxas de juros a índices de preços, processo amplamente disseminado na economia brasileira nas últimas décadas.

2 Quase totalidade, contudo, corresponde aos papéis do Tesouro Nacional.

3 Representado pelo diferencial de remuneração entre as reservas internacionais (ativos) e a dívida interna (passivo). 
Além desta introdução e da conclusão, o artigo está dividido em três seções. Inicialmente, analisa-se o arcabouço institucional da moeda indexada e sua preservação mesmo sob contexto de baixa inflação. A seguir, discute-se a relação entre sustentabilidade macroeconômica e o sistema de indexação dos títulos públicos federais no Brasil, de sorte a especificar a importância de uma gestão da dívida pública que procure reduzir os custos envolvidos no processo de financiamento do setor público. Finalmente, à luz de funções impulso-resposta (FIR) construídas a partir de um Vector Error Correction Model (VECM), a última seção discute os limites que são colocados à gestão da DPMFi no Brasil sob contexto do arcabouço institucional da indexação financeira.

\section{Plano Real e a Persistência da Institucionalidade da Indexação Financeira}

Criadas em 1964-65 no âmbito da reforma financeira realizada por Roberto Campos e Otávio Gouveia de Bulhões, as Obrigações Reajustáveis do Tesouro Nacional (ORTN) passaram a cumprir o papel de instrumento legal para referência de preços, com valor corrigido pela inflação. Sob o contexto de inflação persistente e elevada, este instrumento introduziu o conceito de juro real explícito, ao invés de juros nominais que embutiam uma estimativa de inflação futura.

As ORTN permitiram a recuperação da demanda por dívida pública e a redução do financiamento monetário do Tesouro, além de dar a base para a estruturação do sistema de haveres financeiros e de créditos pósfixados, em especial as cadernetas de poupança e o Sistema Financeiro de Habitação. A coexistência entre operações prefixadas e operações pós-fixadas, corrigidas pelas ORTN e, algumas, pela taxa de câmbio, esteve na base do desenvolvimento financeiro experimentado desde então, e que atingiu seu ápice em meados dos anos 1970 (SILVA, 1979; MINELLA, 1995).

O aumento da utilização das ORTN como referência de preços, contudo, conferiu a esses títulos o papel de quase-moeda ante seu alto grau de liquidez, à medida que a moeda corrente perdeu progressivamente a função de padrão de preços para prazos superiores a algumas semanas ou até mesmo dias.

A volta dos riscos cambiais elevados, com os primeiros sinais da crise da dívida que eclodiria em 1981-82, levou a um progressivo desarranjo do sistema, culminando com a desastrada prefixação da correção monetária e da correção cambial em 1980. Além dos movimentos especulativos que provocou, esta iniciativa quebrou a confiança na expectativa de que a correção das ORTN refletiria a inflação efetiva com margem de erro 
aceitável, confiança que estava na base do sistema em vigor nos anos anteriores (BARROS, 1993).

Os esforços de restabelecimento da confiança na correção monetária levaram ao desenvolvimento progressivo do que se chamaria de indexação financeira, com o estabelecimento de regras implícitas de vinculação entre a correção das ORTN, os juros praticados no overnight e as expectativas de inflação, a partir de 1983. O esforço de quebrar a indexação dos preços no Plano Cruzado, em 1986, levou à forma mais representativa da indexação financeira no Brasil, as Letras do Banco Central (LBC), cujo rendimento era dado pela taxa overnight praticada pelo Banco Central. A volta da indexação em 1987 e os sucessivos momentos de supressão e restabelecimento da indexação a índices de preços, nos anos seguintes, conviveram desde então com esses títulos públicos com rendimento indexado à taxa de juros de curtíssimo prazo. As LBC foram denominadas depois de Letras Financeiras do Tesouro (LFT), sempre corrigidos pela taxa do overnight. No contexto de alta inflação, cumpre salientar, o BC oferecia garantia informal de que os juros de curtíssimo prazo acompanhariam a taxa de inflação, evitando riscos de perdas reais aos credores do setor público (CARVALHO, 1992; MINELLA, 1995).

Com a aceleração dos níveis inflacionários nos anos 1980, a chamada quase-moeda passou a sustentar o chamado tripé da ciranda financeira no Brasil: o governo captava recursos por meio da sinalização de juros reais positivos, os bancos se apropriavam de spreads em operações sem risco, ante o compromisso de "zeragem automática" assumido pela autoridade monetária, e os aplicadores alocavam seus recursos em ativos com liquidez elevada e garantia informal de retorno real.

Com efeito, sob o arcabouço institucional da moeda indexada, a oferta de moeda se tornou quase totalmente endógena, atribuindo passividade à política monetária. Os próprios bancos, pelo mecanismo da "zeragem automática", tornaram-se emissores de moeda indexada, pois eram capazes de oferecer depósitos remunerados ao público com seus ativos alocados quase integralmente em títulos do governo corrigidos pela taxa overnight. Expandiu-se, com isso, a presença da quase-moeda na economia brasileira no decorrer da década de 1980, com os depósitos à vista remunerados, mediante depósitos de um dia no mercado aberto. Esse sistema exigia, de um lado, a atuação dos bancos enquanto compradores de títulos públicos e, de outro, ofertantes de depósitos remunerados junto ao público nãobancário4 ${ }^{4}$ BARROS, 1993).

4 De acordo com Bevilaqua e Garcia (2002, p. 91), "[...] a true dollarization process never ocurred in Brazil, as it happened in other Latin American countries. The reason why that was possible was the provision by the banking sector a good domestic substitute for M1: deposits 
Para os objetivos deste artigo, importa destacar que a despeito de o sistema de indexação ter evitado o fenômeno da substituição monetária e permitido o funcionamento do sistema financeiro no contexto de inflação elevada no Brasil, introduziu-se a possibilidade de os agentes obterem, simultaneamente, proteção contra a inflação e liquidez imediata (e mesmo ganhos reais), condição que propiciou aos bancos, investidores institucionais e grandes grupos industriais e financeiros as bases para manter posições defensivas com alta liquidez e alterá-las de imediato para posições especulativas. A contraparte dessa grande flexibilidade dos aplicadores privados, contudo, foi a dificuldade imposta ao Tesouro e ao BC para realizar uma gestão fiscal e monetária ativa, respectivamente, além do desestímulo à estruturação de um sistema financeiro voltado para o financiamento de longo prazo e orientado para a concessão de recursos para o setor produtivo.

Poder-se-ia esperar que a estabilização monetária permitiria suprimir a indexação financeira. A lógica do Plano Real, todavia, impunha modulações acentuadas e imprevistas da taxa básica de juros, destinadas a garantir o sucesso do plano de estabilização especialmente diante de choques adversos, impondo perdas potenciais aos detentores dos papéis do governo caso estes não fossem atrelados à taxa Selic, em caso de aumento dos juros de curto prazo.

Pode-se afirmar, desse modo, que o financiamento do setor público nessas condições inviabilizou a supressão da indexação financeira depois do Plano Real, a despeito da recuperação das funções clássicas da moeda de curso forçado (ANDIMA, 2003; NAKANO, 2007). De acordo com ANDIMA (2003, p. 65),

A sucessão de profundos choques de juros certamente conspira contra o alongamento das maturidades efetivas dos títulos, porque faz aumentar a probabilidade de ocorrência de graves perdas de capital. É natural que, nessas condições, o prêmio exigido pela compra de papéis de prazo mais longo possa ser inaceitável para o Tesouro, não apenas pelo custo, mas também pelo sinal que seria dado à economia como um todo com relação à fragilidade do futuro. Se a experiência do mercado foi a de que as taxas de juros podem chegar com relativa facilidade a $30 \%$ ou $40 \%$ a.a. - como de fato chegaram repetidamente no passado recente-, esta será a taxa exigida, como piso, para a colocação de papéis de praticamente qualquer maturidade superior a um ano. Mesmo para instituições sensíveis ao risco de renda, o risco de capital seria opressivo na compra de papéis de longa maturidade. Foi exatamente esta situação que levou ao perfil atual da dívida pública, típico

with high liquidity that paid an interest rate high enough to protect from inflation erosion. Banks held public debt on the asset side and offered these interest-bearing deposits as liabilities." 
de uma economia em alerta contra a ocorrência de choques. A indexação dos títulos à Taxa SELIC foi a única saída para lidar com as incertezas criadas pela instabilidade do período.

Além de viabilizar o financiamento da dívida pública nesse contexto, alguns trabalhos sugerem, à luz da teoria das expectativas racionais, que a indexação dos títulos públicos aos juros de curto prazo poderia contribuir para a consistência da política de estabilização monetária. Isto porque, conforme mostrado por Goldfajn e Paula (1999), trabalhos realizados por Calvo (1988), Calvo e Guidotti (1990), Giavazzi e Pagano (1990) e Missale e Blanchard (1994) indicam que a indexação da dívida pública aos juros de curto prazo e/ou ao câmbio funciona como mecanismo de indução para o comprometimento do governo com o controle da inflação, pois reduz a probabilidade de monetização da dívida pública. Ao fazer referência a estes trabalhos, Goldfajn e Paula (1999, p. 7) sustentam que:

Ao diminuir o duration da dívida, aumentando a parcela de títulos indexados, o gestor da dívida fortalece a credibilidade da política antiinflacionária, pois reduz o benefício que poderia levá-lo a inflacionar a economia em períodos posteriores.

Por isso, de acordo com este entendimento, sem o referido mecanismo de indução o mercado exigiria a prevalência de taxa de juros muito alta para financiar o setor público, até que este desfrutasse de plena credibilidade. Nessa perspectiva, oferecendo títulos indexados aos juros de curto prazo, o governo busca sinalizar que a inflação e, ao cabo, a taxa de juros, não irão aumentar. Processo similar ocorre em relação aos títulos indexados à taxa de câmbio, outro preço fundamental da economia. Logo, apenas quando o governo alcançasse uma condição de elevada credibilidade em relação ao seu compromisso com o controle da inflação, o financiamento da dívida pública poderia ser viabilizado a partir de um perfil prefixado, com taxas não-punitivas e prazo alongado de maturação, caso contrário, a composição ótima da dívida, aqui concebida como aquela que minimiza os custos de seu serviço, exigiria a oferta de papéis indexados aos juros de curto prazo e/ou ao câmbio.

Cabe destacar, contudo, à luz da experiência brasileira posterior à estabilização monetária, que a persistência desta estratégia num horizonte de médio e longo prazos, especialmente sob contexto de elevado patamar da taxa de juros, tende a fragilizar a credibilidade do governo, ao invés de aumentá-la, na medida em que potencia o risco de default da dívida pública em contextos de maior instabilidade. Ademais, porém não menos importante, vale observar que alguns autores, como Belluzzo e Almeida (2002) e Carvalho (2005), já haviam apontado que a indexação dos títu- 
los aos juros de curtíssimo prazo terminou por se impor no Brasil pela dificuldade de manter a demanda pelos títulos públicos no contexto de inflação elevada e incerteza cambial persistente, representando, assim, uma alternativa possível para manter a gestão da dívida pública, mas ao custo de criar um quadro de reversão difícil e custoso.

Tem-se, pois, que o Plano Real operou a desindexação de grande parte do setor produtivo da economia, mas não suprimiu o expediente da indexação financeira, aqui entendido como o atrelamento dos títulos públicos federais aos juros de curto prazo definidos pelo Banco Central. Se por um lado essa "parcialidade" do Plano Real foi funcional à estabilização monetária num primeiro momento, ao propósito da estabilização monetária, por outro, a persistência da indexação financeira, mesmo depois de conquistada a estabilidade dos preços e a credibilidade por parte da autoridade monetária, tem implicado constrangimentos para o manejo da política fiscal, em particular, ante a imposição de dificuldades para se viabilizar uma gestão customizada e com maior grau de autonomia da dívida pública.

Dada a persistência da indexação financeira no Brasil e a supressão do trade-off entre risco e retorno dos títulos públicos, não causa surpresa a seguinte afirmação de Bevilaqua e Garcia (2002, p. 92) de que: "In summary, during the megainflation, banks carried public debt to back their interestbearing deposits. [...] That state of affairs not change radically with inflation stabilization." Em contexto de baixa inflação e de juros nominais muito acima da inflação acumulada e esperada, a indexação financeira propiciou a obtenção de juros reais expressivos aos credores do Estado, propiciando a obtenção de ganhos elevados aos credores do Estado mesmo quando da elevação da taxa de juros de curto prazo (Selic).

Pode-se dizer, então, que a indexação financeira passou a operar num ambiente distinto após o Plano Real, convivendo, paradoxalmente, com uma moeda de uso corrente que executa suas três funções básicas. Com a estabilidade monetária, contudo, a indexação financeira deixa de funcionar como "muleta" para a função reserva de valor da moeda corrente de curso forçado e passa a exercer a função de atribuir viabilidade ao financiamento da dívida pública sob contexto de incerteza sobre a taxa básica de juros e de construção da credibilidade da autoridade monetária.

Desse modo, os títulos indexados aos juros de curtíssimo prazo tiveram preservado seu papel de funcionar como ativos líquidos e rentáveis, representando aplicação atrativa para a alocação de poupança financeira dos detentores de riqueza. Mesmo com a recomposição do grau de monetização da economia, o estoque de riqueza continuou sendo aplicado majoritariamente em títulos públicos de curto prazo, ora indexados aos juros de curto prazo quando da expectativa de aumento da taxa de juros, 
ora indexados em títulos prefixados, quando da expectativa de queda dos juros, dificultando a constituição de um sistema financeiro de longo prazo.

Se por um lado a estabilização monetária permitiu ao Banco Central aumentar seu grau de soberania sobre a gestão da moeda, por outro a permanência da indexação financeira, a despeito de ter contribuído para o sucesso no plano no que concerne ao estancamento do processo inflacionário, por outro concorreu para atribuir um comportamento pró-cíclico à DPMFi no Brasil, conforme será evidenciado nas próximas seções. A indexação financeira concorreu ainda para deturpar o canal de ativos da política monetária, condição que impôs elevações ainda maiores da taxa básica de juros quando da ocorrência de choques adversos. ${ }^{5}$

\section{Sustentabilidade Macroeconômica e Indexação Financeira no Brasil}

Nas últimas três décadas, a concepção acerca da gestão da política fiscal sofreu uma evidente transição do enfoque eminentemente keynesiano, que atribui papel fundamental ao instrumento fiscal, especialmente em contextos de insuficiência de demanda efetiva, para o enfoque novoclássico, assentado no modelo da equivalência ricardiana, para o qual o financiamento do setor público mediante emissão de dívida exerce efeito macroeconômico equivalente ao aumento de impostos. De acordo com essa abordagem, diante da perspectiva de aumento da carga tributária no futuro, a renda adicional gerada pelo aumento dos gastos públicos será integralmente poupada pelos agentes, fazendo deixar de existir o efeito multiplicador keynesiano. Esta acepção passa a prevalecer a partir dos anos 1990. ${ }^{6}$ Nas palavras de Hermann (2002, p. 51):

O déficit público não traria, portanto, qualquer benefício em termos de crescimento econômico, tendo, ao contrário, um impacto negativo sobre o bem-estar da sociedade, representado pelo ônus da dívida a ser paga pelas gerações futuras. Daí a recomendação de uma política fiscal de permanente equilíbrio orçamentário.

A neutralidade dos efeitos da política de gasto público no curto prazo, de um lado, e o aumento dos impostos no período subsequente, de outro,

5 A existência de títulos públicos de curtíssimo prazo, com duration praticamente zero e atrelados aos juros de curto prazo, opera no sentido de impedir que o aumento da taxa básica de juros se traduza em redução do valor real presente destes ativos, não provocando uma diminuição na riqueza dos agentes e, ao cabo, do consumo agregado da economia. Por conta disso, Bevilaqua e Garcia (2002, p. 93) afirmam que: "Nevertheless, the main source of vulnerability of the Brazilian economy - the high public sector deficit - is even more adversely affected by the high interest rates that prevailed during the crises period. Those high interest rates, given the debt indexation, do not harm bank's profitability."

6 Em 1992 estabeleceu-se o Pacto de Estabilidade do Contrato de Maastricht, na União Europeia, limitando-se o déficit fiscal a 3\% do PIB e a dívida pública a 60\% do PIB (BENECKE, 2002). 
fazem com que a recomendação de política econômica defendida pela corrente ortodoxa seja a de contenção dos déficits fiscais mediante obtenção de superávits primários, sob a orientação de orçamentos fiscais equilibrados ex-ante e estabilização e/ou redução da relação dívida pública/PIB, de modo a sinalizar ao mercado a solvência do setor público e, assim, garantir o financiamento da dívida sob taxas de juros baixas. De acordo com essa perspectiva, ao invés de a taxa de juros condicionar o estoque de dívida pública, é este que condiciona o comportamento da taxa de juros (HERMANN, 2002).

A despeito das possíveis contestações que podem ser feitas a esta abordagem, seja por negligenciar o efeito-renda contracionista da política de geração de superávits fiscais primários, donde resulta a recomendação de um arranjo que induz uma gestão pró-cíclica da política fiscal; seja por privilegiar o estoque ao invés do fluxo enquanto indicador do grau de solvência do setor público; o fato é que esta acepção tem se mostrado hegemônica nas últimas duas décadas. Não obstante, nos países em que prevalece a prática de juros elevados e, ademais, suscetíveis a oscilações bruscas, a geração de superávits fiscais primários adicionais, tida como necessária para minimizar os efeitos de choques adversos, é neutralizada pelo maior serviço da própria dívida (HERMANN, 2002). A isso se junta, evidentemente, a retração dos negócios provocada pela política econômica mais restritiva, o que geralmente inviabiliza a melhora dos indicadores de solvência (de estoque) do setor público. A indexação financeira provoca, assim, uma inconsistência dinâmica entre as políticas fiscal e monetária.

Conforme se pode observar, existe estreita relação entre as condições macroeconômicas e a composição da dívida pública em termos de indexadores. Mais uma vez de acordo com Hermann (2002, p. 62),

A indexação de grande parte da dívida pública à taxa de juros básica da economia (a taxa Selic) criou uma armadilha para o Banco Central, agravando aquela tendência ao aumento do risco atribuído ao país e ao setor público diante de uma política de juros altos. Diante do elevado peso da dívida indexada à taxa Selic, mesmo um aumento temporário desta taxa pode elevar de forma significativa as despesas financeiras do governo.

A indexação dos títulos públicos à taxa de juros de curto prazo impõe, desse modo, um desequilíbrio potencial e intertemporal às finanças públicas. A reversão dessa situação exige, portanto, um perfil de dívida pública mobiliária com a prevalência de títulos indexados à inflação e/ou prefixados, de sorte a minimizar o impacto dos aumentos da taxa de juros sobre o estoque da dívida pública e atribuir maior eficiência à política monetária, condições que exigiriam um esforço fiscal menor quando da ocorrência de 
choques adversos que imponham a necessidade de aumento da taxa básica de juros, mesmo que transitório. Portanto, o expediente da indexação dos títulos públicos aos juros de curto prazo e/ou ao câmbio pode alterar e instabilizar repentinamente o quadro fiscal, de forma substantiva, quando da ocorrência de choques adversos ${ }^{7}$ (CALVO; GUIDOTTI, 1990; ANDIMA, 2005).

A indexação financeira dificulta, quando não impede, uma gestão anticíclica da política fiscal. Diante de um choque adverso que implique aumento dos preços, a ser contido pelo aumento da taxa básica de juros, a elevação das despesas com juros incide sobre parcela representativa do estoque de dívida pública, o que passa a requerer um ajuste fiscal ainda mais profundo para manter bem comportada a trajetória da relação dívida pública/PIB, aprofundando o choque original. Ou seja, a busca pela estabilidade de preços mediante elevação da taxa de juros implica um aumento instantâneo do serviço da dívida pública, requerendo uma ampliação do superávit fiscal primário e/ou a colocação de títulos adicionais no mercado. ${ }^{8}$ No primeiro caso, amplificam-se os efeitos negativos sobre a renda e o produto ocasionados pelo choque adverso, enquanto no segundo aumenta-se a dívida pública - o que amplia a possibilidade de ocorrência desses mesmos efeitos.

Em simultâneo, o aumento da taxa de juros para conter a inflação reduz o nível de atividade econômica, podendo colocar a relação dívida pública/PIB numa trajetória explosiva quando da prevalência de um nível de superávit fiscal primário insuficiente para neutralizar o aumento da carga de juros que incide sobre dívida pública. A indexação dos títulos públicos aos juros de curto prazo, então, mais uma vez acaba desempenhando um papel nocivo à gestão fiscal, dado que o aumento dos juros incidirá sobre parcela relevante da DPMFi. Restringe-se, com isso, a própria autonomia da gestão da política monetária, fazendo com que a obtenção de credibilidade tenha um custo ainda maior.

Não menos importante, a elevada participação dos títulos públicos atrelados à taxa Selic torna a duration da DPMFi praticamente nula, a

7 A indexação faz com que, sob situações de stress, de acordo com Blanchard (2004), um aumento da taxa de juros para fazer com que a inflação convirja para a meta, ao invés de provocar apreciação cambial, impulsiona a depreciação, dado o aumento do risco de default da dívida pública, fazendo a inflação aumentar ainda mais. Dificulta, então, a própria operação do regime de metas para a inflação.

8 O regime de metas para inflação, então, funciona intrinsecamente enquanto antídoto ao problema da "dominância fiscal", tal como formulado por Sargent e Wallace (1981). Isso porque o excesso de gasto da autoridade fiscal não pode ser monetizado pela autoridade monetária, dado que isso implicaria desvio adicional do comportamento dos preços em relação à meta preestabelecida para a inflação. É interessante notar, ademais, a acepção eminentemente monetarista nas relações de interdependência indicadas. 
despeito de poder contribuir para o alongamento dos prazos dos papéis. A própria dilatação dos prazos dos papéis, contudo, faz com que se prorrogue a ineficácia do canal de ativos da política monetária, uma vez que impõe exclusivamente ao emissor o risco de variação da taxa de juros. ${ }^{9}$ Decorre, pois, que sob contexto de "indexação financeira", o gerenciamento da DPMFi fica em grande medida condicionado pelas expectativas dos agentes em relação às modulações vindouras e de curto prazo das variáveis que servem de indexadores aos papéis do governo. Isto faz com que o perfil DPMFi passe a ter um comportamento que independe, em certa medida, das metas e orientações estabelecidas pela Secretaria do Tesouro Nacional, reduzindo seu grau de autonomia na gestão da dívida pública (ANDIMA, 2003).

Portanto, pode-se concluir que a indexação de boa parte da DPMFi à taxa de juros de curto prazo dificulta, quando não impede, uma gestão da dívida que busque minimizar o custo de seu serviço, tal como geralmente ocorre nos países com mercado de títulos públicos desenvolvidos e profundos. Sob a institucionalidade da indexação financeira, medidas que procurem ampliar a liquidez dos papéis no mercado secundário e aumentar a eficiência do mercado de títulos públicos tendem a ter efeitos reduzidos, dado que a indexação dos papéis aos juros de curto prazo torna quase irrelevante o risco de mercado. Isso porque a indexação financeira faz com que, nas palavras da ANDIMA (2003, p. 48-49),

Para efeito de risco, tudo se passa como se o papel fosse liquidado e reemitido com novas taxas sempre que os juros de curtíssimo prazo oscilassem. Não havendo risco de mercado, não há por que buscar instrumentos que defendam o investimento contra movimentos inesperados de juros. Pela mesma razão, também não prosperam instrumentos como a venda short, que de algum modo representa uma aposta em mudança das taxas de juros no futuro (e, assim, nos preços de mercado dos títulos).

O risco de liquidez, por sua vez, também é inexpressivo, mas em função da baixa maturidade da maior parte do estoque de títulos e da aparente disposição das autoridades de adaptar as regras de operação do mercado, de modo a facilitar a continuidade de colocação de papéis na eventualidade de

9 A indexação da dívida pública à taxa de juros de curto prazo definida pelo Banco Central gera uma anomalia no canal de ativos da política monetária: o aumento da taxa de juros não impõe perda de capital aos detentores de títulos públicos, o que exige aumentos maiores do que os necessários, caso os títulos não fossem indexados à taxa Selic, para que se viabilize o alcance de determinados objetivos de política econômica. $\mathrm{O}$ aumento da taxa de juros acaba produzindo um aumento do valor presente da riqueza para os detentores de Letras Financeiras do Tesouro (LFT), condição que neutraliza, ao menos parte, o efeito contracionista sobre a demanda agregada (ANDIMA, 2005). 
qualquer movimento adverso. Assim, o preço dos títulos perde importância. Se os papéis têm duração efetiva muito curta, o que importa é o seu rendimento, não a flutuação dos preços em mercados secundários. Se apresentam duração mais longa, seus preços não sofrem nenhuma redução no caso de elevação de juros, já que o rendimento esperado é automaticamente corrigido pela nova taxa.

Com os riscos de crédito virtualmente inexistentes, e os de mercado e de liquidez significativamente amenizados, não surpreende que os instrumentos desenvolvidos para melhorar a relação entre risco e retorno de papéis públicos se tornem inócuos.

A indexação dos títulos públicos aos juros de curto prazo, então, ao impor um elevado grau de incerteza sobre as despesas com o serviço da dívida, além de impedir uma gestão "customizada" da dívida pública, acaba acarretando ônus à própria gestão da política fiscal: do lado da receita, contribui para impedir, ainda que indiretamente, uma estrutura tributária menos onerosa e uma carga tributária menos punitiva; do lado das despesas, por sua vez, enseja cortes orçamentários não raro em serviços essenciais, em prol da remuneração dos títulos detidos em sua maior parte por instituições financeiras e investidores institucionais. ANDIMA (2003, p. 53) sintetiza muito bem os problemas gerados pela indexação generalizada da DPMFi:

A incerteza que cerca as despesas com o serviço da dívida, resultante da indexação generalizada dos papéis, prejudica a racionalidade do processo de gestão orçamentária do setor público e acaba tendo impacto negativo sobre o nível da atividade econômica no país. As práticas que hoje regem a remuneração da dívida pública parecem inconciliáveis com os trade-offs entre risco e retorno que permitiriam o desenvolvimento de um mercado de títulos privados e o financiamento das atividades privadas em geral. Impõe-se, portanto, a reordenação do mercado de títulos públicos, de modo a viabilizar a diversificação dos papéis, a atração de novos investidores e a obtenção de combinações mais adequadas entre risco e retorno.

Apenas a título indicativo, posto que ultrapassa os objetivos deste artigo, cumpre registrar que a indexação financeira concorre para gerar uma série de outras anomalias em diferentes âmbitos. Ou seja, o expediente da aqui chamada "indexação financeira" transcende os problemas estritamente relativos à gestão da dívida pública, exercendo impactos negativos sobre as condições de financiamento e, ao cabo, sobre a economia como um todo. Destacam-se as seguintes:

a) dificulta, quando não impede, a construção de uma yield curve positivamente inclinada e que sirva de balizamento para a precificação de 
títulos privados de prazos similares e de âncora de expectativas dos agentes, condição que potenciaria a obtenção de funding pelas empresas e, ao cabo, contribuiria para a dinamização do ciclo de negócios ${ }^{10}$ (ANDIMA, 2003);

b) ao suprimir o trade-off entre risco e retorno, a indexação dos títulos públicos federais à taxa Selic obstaculiza o aprofundamento do mercado de títulos privados;

c) a existência de um ativo ao mesmo tempo líquido e rentável provoca distorções alocativas e, suplementarmente, pode contribuir para a "restrição financeira", dado que os bancos embutem em suas taxas de juros de suas operações de crédito o custo de oportunidade representado pelos retornos monetários e não-monetários oferecidos pelos títulos públicos federais (OLIVEIRA; CARVALHO, 2007);

d) faz com que todo o mercado seja orientado para o segmento mais curto, inviabilizando a coordenação entre as políticas monetária e fiscal e, consequentemente, impedindo uma gestão eficiente da DPMFi, capaz de minimizar seus custos financeiros e ampliar sua duration (ANDIMA, 2003; MENDONÇA, 2004); enseja, ainda, uma falta de coordenação entre as políticas monetária e fiscal, o que afeta negativamente a performance macroeconômica do país (LAURENS; LA PIEDRA, 1998);

e) a participação de parcela expressiva dos títulos públicos atrelados à taxa de juros de curto prazo na DPMFi faz com que, à luz do modelo Giavazzi-Pagano (1990), a capacidade do governo de conter crises de confiança seja bastante reduzida, mesmo sob câmbio flexível. Isso torna a administração da dívida pública incapaz de contornar crises de confiança a custos baixos;

f) a indexação de importante parcela da DPMFi aos juros de curto prazo determinados pela autoridade monetária implica um comportamento pró-cíclico da DPMFi no Brasil, além de introduzir uma situação de "dominância monetária", ao invés de "dominância fiscal". Diante de

10 Essa situação, no Brasil, é ainda mais problematizada pela inexistência, ao contrário dos Estados Unidos, de uma segmentação de mercado de títulos que permita uma diferenciação das esferas de atuação da autoridade monetária e do Tesouro Nacional, o que faz com que a taxa de juros seja determinada pelas metas de política monetária, ao invés de ser orientada para a redução do custo de carregamento da dívida pública, condição que atribuiria maior flexibilidade à política fiscal (ANDIMA, 2003). Nos Estados Unidos, de acordo com ANDIMA (2003, p. 62), a política monetária é operada apenas mediante às letras do Tesouro, sendo da alçada da autoridade monetária apenas o preço das reservas bancárias. O Departamento do Tesouro, por seu turno, responsável pela administração da dívida pública, define os procedimentos em relação às notas e bônus. 
choques adversos, o expediente da indexação financeira afeta negativamente o grau de credibilidade e os mecanismos de sinalização da autoridade monetária. Concorre, ainda, no sentido de potenciar o ônus orçamentário decorrente do aumento da taxa básica de juros da economia, a Selic.

\section{Indexação Financeira e Comportamento Pró-cíclico da DPMFi: um Modelo VECM}

Para analisar os efeitos da "indexação financeira" sobre a participação dos títulos atrelados aos juros de curto prazo na DPMFi, fez-se uso de um modelo de Vetores Autorregressivos (VAR) contendo as seguintes variáveis: participação dos títulos indexados à Selic na dívida pública mobiliária federal; taxa de câmbio nominal; inflação medida pelo IPCA acumulada nos últimos 12 meses; e taxa de juros Selic acumulada no mês anualizada. Considerou-se o período jan. 00/mar. 07, ${ }^{11}$ envolvendo um número de 87 observações para cada variável, permitindo a construção de um modelo VAR com um número razoável de parâmetros, dado que estes crescem substantivamente com o número de variáveis do modelo e com o número de lags (PATTERSON, 2000).

O objetivo do exercício foi analisar o comportamento da participação dos títulos públicos indexados aos juros de curto prazo frente às modulações das variáveis macroeconômicas mencionadas. Isso porque a indexação financeira faz com que um aumento da taxa Selic tenda a aumentar a participação de títulos públicos indexados à taxa básica de juros na DPMFi; um mesmo movimento pode se esperar com uma desvalorização cambial, que ao pré-anunciar um aumento da inflação, exige o aumento da taxa básica de juros. Esta dinâmica induz a prevalência de uma gestão pró-cíclica da DPMFi. O modelo proposto busca, então, analisar os impactos das variáveis selecionadas sobre a parcela da DPMFi atrelada aos juros de curto prazo.

Um modelo de Vetores Autorregressivos (VAR) consiste num conjunto de k regressões de séries de tempo, onde os regressores são valores defasados de todas as k séries. Com isso, a autorregressão univariada é estendida para um vetor de variáveis de séries temporais (STOCK; WATSON, 2004). Considerando um sistema simples bivariado, com $\mathrm{Y}_{\mathrm{t}}$ e $\mathrm{Z}_{\mathrm{t}}$ estacionários e $\varepsilon_{\mathrm{yt}}$ e $\varepsilon_{\mathrm{zt}}$ os distúrbios ruído-branco, não correlacionados e com desvio padrão dado por $\sigma_{\mathrm{y}}$ e $\sigma_{\mathrm{x}}$, sob um VAR de primeira ordem tem-se:

11 Início da série histórica da participação dos títulos indexados à Selic na dívida pública mobiliária federal, posição em carteira (série 4177 das séries temporais do Banco Central). 


$$
\begin{aligned}
& Y_{t}=b_{10}-b_{12} Z_{t}+\gamma_{11} Y_{t-1}+\gamma_{12} Z_{t-1}+\varepsilon_{y t} \\
& Z_{t}=b_{20}-b_{21} Z_{t}+\gamma_{21} Y_{t-1}+\gamma_{22} Z_{t-1}+\varepsilon_{z t}
\end{aligned}
$$

sendo os $b_{s}$ e os $\gamma_{s}$ os coeficientes desconhecidos, estimados por Mínimos Quadrados Ordinários (MQO); e $\varepsilon_{1 \mathrm{t}} \varepsilon_{2 \mathrm{t}}$ Os termos de erro, os choques sobre $Y_{t}$ e $Z_{t}$, respectivamente. Nota-se que $Y_{t}$ é afetado pelo efeito contemporâneo da mudança de $Z_{t}$, dado pelo coeficiente $b_{12}$, bem como pelas mudanças passadas da própria variável e da variável $Z_{\mathrm{t}}$, dados pelos parâmetros $\gamma_{11}$ e $\gamma_{12}$, respectivamente. $\gamma_{21}$ corresponde ao efeito de $Y_{t-1}$ sobre $Z_{\mathrm{t}}$. Decorre, então, que se $\mathrm{b}_{21}$ for diferente de zero, $\varepsilon_{\mathrm{yt}}$ exercerá um efeito contemporâneo indireto sobre $Z_{\mathrm{t}}$, assim como se $\mathrm{b}_{12}$ for diferente de zero, $\varepsilon_{z t}$ exercerá impacto indireto contemporâneo sobre $Y_{t}$ (ENDERS, 1995).

Mas como $Z_{t}$ exerce efeitos contemporâneos sobre $Y_{t}$ e vice-versa, $o$ que conforma um VAR estrutural ou sistema primitivo, pode-se estimar uma forma mais usual mediante a utilização de álgebra matricial. Tem-se, então, o seguinte VAR reduzido:

$$
\begin{aligned}
& Y_{t}=a_{10}-a_{11} Y_{t-1}+a_{12} Z_{t-1}+e_{1 t} \\
& Z_{t}=a_{20}-a_{21} Y_{t-1}+a_{22} Z_{t-1}+e_{1 t}
\end{aligned}
$$

com $\mathrm{a}_{10}$ correspondendo ao i do vetor $\mathrm{A}_{0}$, dado por $\mathrm{B}^{-1} \Gamma \mathrm{n} ; \mathrm{a}_{\mathrm{ij}}$ como o elemento na linha i e coluna j da matriz $\mathrm{A}_{1}$, dado por $\mathrm{B}^{-1} \Gamma_{1}$; e $\mathrm{e}_{\mathrm{it}}$ como elemento i do vetor $\mathrm{e}_{\mathrm{t}}$, dado por $\mathrm{B}^{-1} \varepsilon_{\mathrm{t}}$. Esta transformação se faz necessária porque devido ao feedback inerente ao sistema, que faz com que $Z_{t}$ seja correlacionado com o termo de erro $\varepsilon_{\mathrm{yt}}$ e $\mathrm{Y}_{\mathrm{t}}$ com o termo de erro $\varepsilon_{\mathrm{zt}}$, as equações do VAR estrutural não podem ser estimadas diretamente ${ }^{12}$ (ENDERS, 1995).

Com o modelo VAR desenvolvido, procurou-se analisar as relações de interdependência entre as variáveis de séries temporais apresentadas. Este objetivo, cumpre salientar, encontra-se em sintonia com a proposta original de Sims (1980) para a utilização de VARs. Uma das grandes vantagens de se trabalhar com modelo VAR é que todas as variáveis do sistema são consideradas endógenas, prerrogativa bastante sintonizada com as relações causais usuais entre as variáveis macroeconômicas, pois permite um sistema de relações causais diretas e indiretas entre as variáveis do sistema. De acordo com Patterson (2000, p. 600), "In a VAR $y_{1 t}$ is related not just to its own lagged values but also those of $y_{2 t}$, and similarly $y_{2 t}$ is related to its own lagged values and those of $y_{1 t}$.

A Figura 1 (ver Apêndice) apresenta as variáveis em nível contempladas no modelo, quais sejam: participação dos títulos públicos atrela-

12 De acordo com Enders (1995, p. 302, tradução nossa), as "Técnicas de estimação padrão requerem que os regressores sejam não-correlacionados com os termos de erro". 
dos à taxa Selic na DPMFi (Div_pos), posição em carteira (série 4177 das séries temporais do Banco Central); taxa Selic acumulada no mês anualizada (Selic), em \% ao ano (série 4189 das séries temporais do Banco Central); inflação medida pelo IPCA acumulada nos últimos 12 meses (Infl), em \% (calculada com base na série 433 das séries temporais do Banco Central); e taxa de câmbio nominal (Câmbio), venda e fim de período (série 3696 das séries temporais do Banco Central). ${ }^{13}$ Todas as variáveis foram transformadas em logarítimos neperianos.

De modo a verificar a existência de raiz unitária nas séries consideradas, que impede a utilização das estatísticas de teste convencionais, fez-se necessária a realização de testes de raiz unitária. Dado que todas as séries consideradas apontam ter como hipótese alternativa razoável ao caminho aleatório a possibilidade de girarem em torno de uma média diferente de zero, realizou-se o teste ADF com intercepto (tau $\mu$ ) para todas as séries, com os lags determinados pelo critério de informação de Schwartz. Os resultados do teste Dickey-Fuller Aumentado (ADF) são apresentados na Tabela 1 (ver Apêndice).

Os resultados do teste mostram que em todas as séries contempladas em nível não se pode rejeitar a hipótese de não-estacionariedade, com nível de significância de 5\%, mas se pode rejeitar a hipótese de não-estacionariedade em $1^{a}$ diferença, com nível de significância de $1 \%$. Pode-se dizer, pois, que de acordo com o teste $\mathrm{ADF}$ não se pode rejeitar a hipótese de que as variáveis macroeconômicas selecionadas são integradas de ordem 1 , I(1). Na Figura 2 (ver Apêndice) são apresentados os gráficos das séries em $1^{\mathrm{a}}$ diferença.

Deste modo, realizou-se o teste de cointegração de Johansen para a verificação de existência de relação de cointegração entre as variáveis, ou seja, a possibilidade de a combinação linear entre variáveis não-estacionárias produzir erros estacionários. Para isso, rodou-se um VAR com 3 lags, estabelecidos a partir do critério de informação de Akaike. O VAR apresentou normalidade dos resíduos, pelo teste Jarque Bera aplicado ao VAR pelo método de Cholesky a 1\% de significância (Tabela 2 do Apêndice), ausência de correlação serial, tomando-se por base o teste LM aplicado ao VAR (Tabela 3 do Apêndice), e ausência de heterocedasticidade a $5 \%$ de significância, considerando o teste de White (Tabela 4 do Apêndice). Realizou-se, ademais, o teste de Block Exogeneity Wald Test (Granger/ Wald) para a definição de uma ordenação estatisticamente consistente das variáveis do modelo (Tabela 5 do Apêndice). As variáveis devem ser ordenadas das mais exógenas (menores valores da estatística) para as mais endógenas (maiores valores da estatística). Nessa perspectiva, a ordenação considerada consistente foi dada por: câmbio, inflação, Selic e Div_pos.

13 Todas as séries podem ser acessadas no site do Banco Central do Brasil (www.bcb.gov.br). 
Pelo fato de as variáveis do VAR estimado serem I (1), a não-estacionariedade e a instabilidade do VAR pode ser diagnosticada pela existência de raiz unitária no polinômio autorregressivo característico, dada a existência de um dos autovalores da matriz com módulo igual a um ${ }^{14}$ (Figura 3 do Apêndice). Uma primeira opção seria trabalhar com um VAR em primeira diferença. Um modelo em primeira diferença, contudo, mostra-se muito pouco intuitivo. Não menos importante, caso exista uma relação de cointegração entre as variáveis, a estimação do VAR em primeira diferença se traduz num erro de especificação do VAR, ante a não captação das relações de longo prazo entre as variáveis. Nos termos de Patterson (2000, p. 602): [...] ommiting the cointegration combination is a specification error in a VAR in first differences and, in addition, such a VAR provides no information about the long run which is often of considerable interest to economists.

Nesta perspectiva, realizou-se o teste de cointegração de Johansen (Tabela 6 do Apêndice). Considerando-se um VAR com 3 lags e constante, não foi possível rejeitar a hipótese de existência de ao menos um vetor de cointegração, tanto pela estatística de traço, a 5\% de significância, quanto pela estatística de máximo autovalor, a 10\% de significância. A existência de uma relação de cointegração entre as variáveis do modelo permitiu, então, rodar um Vector Error Correction Model (VECM), agora com 2 lags ao invés de 3 , dado que se passou a trabalhar em primeira diferença ${ }^{15}$ (Figura 4 do Apêndice). Este procedimento permitiu, pois, captar as relações de longo prazo entre as variáveis do modelo. Mantendo-se a ordenação sugerida pelo teste de Granger/Wald e considerando-se o método de decomposição de Cholesky, foram rodados os gráficos de impulsoresposta para o VECM (Figura 5 do Apêndice), bem como a tabela com a decomposição da variância da variável Div_pos (Tabela 9). Tais procedimentos se fizeram oportunos diante das dificuldades de se analisar os parâmetros do VAR estrutural, especialmente a partir de sua forma reduzida. As funções de impulso-resposta (FIR), porém, são mais do que suficientes para o alcance do principal objetivo proposto no artigo. Segundo Silva, Oreiro e Paula (2007, p. 215),

A função impulso-resposta é utilizada para fazer uma análise da sensibilidade de determinadas variáveis a certos choques, sendo útil principalmente para

14 De acordo com Patterson (2000, p. 604), "The necessary and sufficient condition for stability in a first order VAR is that all the eigenvalues of $\prod 1$ have modulus less than $1 . "$

15 O VECM, conforme se pode observar na Figura 4, contempla as variáveis em nível, multiplicados pelos correspondentes coeficientes de cointegração, o que implica ganhos expressivos na comparação com um VAR em primeira diferença, muito pouco intuitivo pelas razões já indicadas - opção a ser seguida caso não houvesse uma combinação linear entre as variáveis I (1) que produzisse erros estacionários. 
conhecer o tempo, a direção, o padrão de reação das respostas aos impulsos (choque) de um desvio-padrão sobre os valores contemporâneos e futuros das variáveis endógenas do sistema.

As funções impulso-resposta do VECM oferecem evidências acerca do papel desempenhado pela indexação dos títulos públicos federais aos juros de curto prazo. Considerando a última linha dos gráficos de impulsoresposta, observa-se que um choque no câmbio tende a provocar um aumento substantivo na participação dos títulos públicos atrelados à taxa Selic na DPMFi, o mesmo ocorrendo com um choque na inflação. Pode-se dizer que isto ocorre porque tanto o aumento da taxa de câmbio, como da inflação, provoca um aumento da taxa Selic, conforme se pode verificar nos primeiro e terceiro gráficos da segunda linha, respectivamente. Portanto, uma desvalorização do câmbio ou uma pressão inflacionária, ao sinalizar um aumento da Selic e aumentar o grau de incerteza dos atores econômicos, provoca um forte aumento da participação dos títulos indexados à Selic na DPMFi.

Um choque no crescimento da Selic, por seu turno, também provoca um aumento da parcela dos títulos atrelados aos juros de curto prazo da $\mathrm{DPMFi}$, embora sob menor intensidade do que os choques no crescimento do câmbio e da inflação. Este resultado encontra-se em sintonia com o obtido por Mendonça (2004, p. 66), que a partir de um modelo VAR de ordem 2 contemplando as variáveis prazo médio da dívida pública, taxa Selic e participação dos títulos públicos indexados à taxa Selic, mostrou a importância da taxa Selic na determinação da "parcela Selicada" da DPMFi. Em seu modelo, a taxa Selic e o prazo médio da dívida pública mostraram-se importantes para a variação da participação dos títulos indexados aos juros de curto prazo na DPMFi. Por conta disso, o autor sustenta que a rigidez à baixa da taxa Selic no Brasil decorre da estrutura inadequada de indexação da dívida pública. Em sintonia com o argumento sustentado neste artigo, Mendonça (2004, p. 70-71) afirma que:

Uma possível forma de ampliar o prazo médio da dívida pública e reduzir as pressões sobre a taxa de juros é realizar uma mudança na composição da estrutura de indexação da dívida. É preciso que se reduza a proporção de títulos atrelados à taxa SELIC e ao câmbio e seja aumentado o volume de títulos indexados à inflação. Deste modo, elevações na taxa de juros para arrefecer pressões inflacionárias também contribuiriam para reduções na razão dívida/PIB. Por conseguinte, haveria um incremento na credibilidade da política anti-inflacionária que favoreceria a estratégia de ampliação do prazo da dívida pública.

Na mesma direção, a ANDIMA (2003, p. 54) salienta que: 
A eliminação da indexação não apenas permitirá um aumento do grau de racionalidade na gestão fiscal do governo, como tornará mais transparentes os trade-offs risco/retorno efetivamente aceitos neste segmento do mercado financeiro, de modo que sirvam de referência para operações com papéis privados.

O modelo desenvolvido neste artigo permite conjeturar, pois, que a indexação dos títulos públicos aos juros de curto prazo impõe um comportamento pró-cíclico da DPMFi no Brasil. Diante de qualquer incerteza que preanuncie a prática de uma política monetária restritiva, como o aumento da inflação ou a desvalorização da taxa de câmbio, os credores do setor público rapidamente compram papéis atrelados aos juros de curto prazo, fazendo com que o aumento da taxa Selic provoque forte expansão da DPMFi e, ao cabo, da própria relação Dívida Pública/PIB ante o crescimento das despesas com juros e a redução do crescimento econômico induzidos pelo aumento dos juros de curto prazo.

A decomposição da variância da parcela da DPMFi indexada aos juros de curto prazo mostra que, num horizonte de 24 meses, cerca de $80 \%$ de sua variação pode ser explicada pela variação da inflação e do câmbio em conjunto (Tabela 7), dada a importância dessas variáveis na variação da taxa Selic, conforme pode ser atestado pela Tabela 8, que mostra a decomposição da variância da taxa Selic acumulada no mês anualizada. Isso porque as variações do câmbio e da inflação normalmente pré-anunciam mudanças na taxa de juros ${ }^{16}$ - cujo objetivo, considerando o arcabouço institucional de política monetária prevalecente a partir de meados de 1999, consiste em viabilizar o cumprimento da meta para a inflação.

Considerando as variáveis selecionadas e o período contemplado no modelo, pois a taxa de juros tem seu efeito máximo sobre a variação da "parcela Selicada" da DPMFi por volta do sexto mês, período em que responde por cerca de 7,5\% da variação da Div_pos. Isso não significa, porém, que a taxa de juros tem impacto irrelevante sobre a participação dos títulos atrelados à Selic na DPMFi, mas justamente o contrário, pois conforme já salientado, as variáveis câmbio e inflação sinalizam mudanças da taxa básica de juros da economia, a Selic.

16 Esta relação de precedência temporal entre as variáveis indicadas pôde ser sustentada pelos resultados do teste de precedência temporal de Granger, realizado no Eviews 4.1. Para a realização do teste, trabalhou-se com as séries em primeira diferença, considerando que não se pode rejeitar a hipótese de que as séries selecionadas neste artigo são integradas de ordem 1. Fez-se necessário trabalhar com os dados em $1^{\text {a }}$ diferença para realizar o teste porque, de acordo com Gujarati (2006, p. 635), "[...] os testes de causalidade de Granger e Sims [...] pressupõem que as séries temporais envolvidas na análise são estacionárias". Os resultados do teste permitem rejeitar as hipóteses, com nível de significância de 5\%, que o câmbio não causa inflação e que a inflação não causa Selic no sentido de Granger. 


\section{Considerações finais}

O artigo discutiu as implicações da existência de títulos públicos atrelados aos juros de curto prazo sobre o comportamento da DPMFi no Brasil. Pôde-se verificar, a partir de um VECM, que a participação dos títulos indexados à taxa Selic na DPMFi se mostra altamente responsiva às modulações das variáveis câmbio, inflação e, ainda que em menor grau, taxa Selic, condição que sugere a pró-ciclicidade da gestão da DPMFi no Brasil. Por sinalizar um aumento da taxa de juros, a elevação da inflação e a desvalorização da taxa de câmbio concorrem no sentido de aumentar a parcela de títulos indexados aos juros de curto prazo na DPMFi, potenciando os custos fiscais inerentes à prática de uma política monetária restritiva e neutralizando parte dos efeitos da política de superávits fiscais primários sobre a dívida pública. Quando a inflação cai ou o câmbio se aprecia, por outro lado, a parcela de títulos indexados à Selic na DPMFi tende a ser reduzida, minimizando o impacto da queda da taxa Selic sobre as despesas com juros do setor público.

A manutenção de um dos principais pilares do arcabouço institucional da "moeda indexada" no Brasil mesmo sob contexto de estabilidade monetária, representado pela existência de títulos públicos atrelados aos juros de curto prazo (indexação financeira), se por um lado contribuiu para atribuir viabilidade ao financiamento do setor público e à construção de credibilidade da autoridade monetária num contexto de elevado risco de perda de capital para os detentores de papéis do governo, por outro implicou fortes restrições para o manejo da DPMFi. As evidências apresentadas no artigo sugerem que a indexação financeira atribui um comportamento pró-cíclico à DPMFi, condição que restringe o grau de autonomia do Tesouro na gestão da dívida pública.

A realização de mais estudos sobre o tema constitui condição necessária para que sejam vislumbradas alternativas voltadas a propiciar a conformação de um arranjo institucional capaz de reduzir os custos impostos pela política monetária à dívida pública, permitir uma gestão fiscal com maior grau de autonomia e incentivar as operações de longo prazo.

\section{Referências}

ASSOCIAÇÃO NACIONAL DAS INSTITUIÇÕES DO MERCADO FINANCEIRO (ANDIMA). Dívida pública: participação do investidor estrangeiro. Rio de Janeiro: ANDIMA, 2005.

. Dívida pública: propostas para ampliar a liquidez. Rio de Janeiro: ANDIMA, 2003.

BARROS, L. C. M. A moeda indexada: uma experiência brasileira. Economia e Sociedade, Campinas, n. 2, p. 3-24, ago. 1993. 
BELLUZZO, L. G. M.; ALMEIDA, J. G. Depois da queda: a economia brasileira da crise da dívida aos impasses do Real. Rio de Janeiro: Civilização Brasileira, 2002.

BENECKE, D. W. Dívida pública: um tema sem final feliz? In: HERRERA, S. et al. Dilemas da dívida. Rio de Janeiro: Fundação Konrad Adenauer, 2002. p. 199-207.

BEVILAQUA, A. S.; GARCIA, M. G. P. Banks, domestic debt, and crises: the recent brazilian experience. Revista de Economia Política, São Paulo, v. 22, n. 4, p. 85-103, out./dez. 2002.

BLANCHARD, O. Fiscal dominance and inflation targeting: lessons from Brazil. NBER Working Paper, n.10389, march 2004.

CALVO, G. Servicing the public debt: the role of expectations. American Economic Review, v. 78, n. 4, p. 647-661, 1988.

CALVO, G.; GUIDOTTI. Indexation and maturity of government bonds: an exploratory model. In: DORNBUSCH, R.; DRAGHI, M. (Ed.). Public debt management: theory and history. Cambridge: Cambridge University Press, 1990. p. 52-93.

CARNEIRO, R. Desenvolvimento em crise: a economia brasileira no último quarto do século XX. São Paulo: UNESP; IE/Unicamp, 2002.

CARVALHO, C. E. Dívida pública: um debate necessário. In: SICSÚ, J.; PAULA, L. F.; MICHEL, R. Novo-desenvolvimentismo: um projeto nacional de crescimento com equidade social. Barueri: Manole; Rio de Janeiro: Fundação Konrad Adenauer, 2005. p. 379-399.

. Liquidez e choques antiinflacionários. In: BATISTA Jr., P. N.; BELLUZZO, L. G. M.

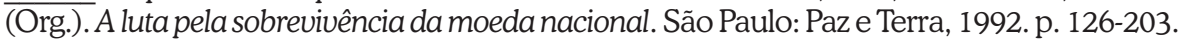

ENDERS, W. Applied econometric time series. USA: Wiley, 1995.

FRANCO, G. H. B. O Plano Real e outros ensaios. Rio de Janeiro: Francisco Alves, 1995.

GIAVAZZI, F.; PAGANO, M. Confidence crises and public debt management. In: DORNBUSCH, R.; DRAGHI, M. (Ed.). Public debt management: theory and history. Cambridge: Cambridge University Press, 1990.

GOLDFAJN, I.; PAULA, A. Uma nota sobre a composição ótima da dívida pública: reflexões para o caso brasileiro. Texto para Discussão, Rio de Janeiro: Departamento de Economia da PUCRJ, n. 411, dez. 1999.

GOMES, C.; HOLLAND, M. Regra de Taylor e política monetária em condições de endividamento público no Brasil. In: ENCONTRO NACIONAL DE ECONOMIA, 31., 2003, Porto Seguro. Anais eletrônicos... Porto Seguro, 2003. Disponível em: <http://www.anpec. org.br/encontro_2003.htm>. Acesso em: 10 jun. 2007.

GUJARATI, D. Econometria básica. 4. ed. Rio de Janeiro: Elsevier, 2006.

HERMANN, J. A macroeconomia da dívida pública: notas sobre o debate teórico e a experiência brasileira recente. In: HERRERA, S. et al. Dilemas da divida. Rio de Janeiro: Fundação Konrad Adenauer, 2002. p. 41-70.

HERRERA, S. A dívida pública brasileira: uma perspectiva internacional. In: HERRERA, S. et al. Dilemas da dívida. Rio de Janeiro: Fundação Konrad Adenauer, 2002. p. 11-40.

LAURENS, B.; LA PIEDRA, E. G. Coordination of monetary and fiscal policies. IMF Working Paper: International Monetary Fund, n. 25, mar. 1998.

MENDONÇA, H. F. Três ensaios sobre a dívida pública e a determinação da taxa de juros na economia brasileira. In: SECRETARIA DO TESOURO NACIONAL (Org.). VIII Prêmio 
Tesouro Nacional. Brasilia: Universidade de Brasilia, 2004. Disponível em: <www.stn.fazenda. gov.br/Premio_TN/VIIIPremio/2premio_afdp.pdf > . Acesso em: 10 jun. 2007.

MINELLA, A. A indexação dos contratos financeiros em contexto de alta inflação: o caso brasileiro (1964-1990). 246 f. Dissertação (Mestrado em Economia) - Instituto de Economia, Universidade Estadual de Campinas, Campinas, 1995.

MISSALE, A.; BLANCHARD, O. The debt burden and the debt maturity. American Economic Review, New York, v. 84, n. 1, mar. 1994.

NAKANO, Y. A taxa de juros mais alta do mundo deverá persistir. Conjuntura Econômica, Rio de Janeiro, jan. 2007.

OLIVEIRA, G. C.; CARVALHO, C. E. O componente "custo de oportunidade" do spread bancário no Brasil: uma abordagem pós-keynesiana. Economia e Sociedade, Campinas, v. 16, n. 3, p. 371-404, dez. 2007.

PATTERSON, K. An introduction to applied econometrics: a time series approach. New York: Palgrave, 2000.

PERRON, P. P. The great crash, the oil price shock and the unit root hypothesis. Econometrica, V. 57, n. 6, p. 1361-1401, nov. 1989.

SANTOS, C. H.; PIRES, M. C. C. Qual a sensibilidade dos investimentos privados a aumentos na carga tributária brasileira? Uma investigação econométrica. Mimeografado, 2007.

SARGENT, T. J.; WALLACE, N. Some unpleasant monetarist arithmetic. Quarterly Review, Federal Reserve Bank of Minneapolis, p.1-17, Fall, 1981.

SILVA, A. M. Intermediação financeira no Brasil: origens, estrutura e problemas. São Paulo: FEA/USP, 1979.

SILVA, G. J. C.; OREIRO, J. L. C.; PAULA, L. F. Spread bancário no Brasil: uma avaliação empírica recente. In: PAULA, L. F.; OREIRO, J. L. C. Sistema financeiro: uma análise do setor bancário brasileiro. Rio de Janeiro: Campus, 2007. p. 191-220.

SIMS, C. A. Macroeconomics and reality. Econometrica, v. 48, n. 1, p.1-48, 1980.

STOCK, J. H.; WATSON, M. W. Econometria. São Paulo: Pearson, 2004. 


\section{Apêndice}

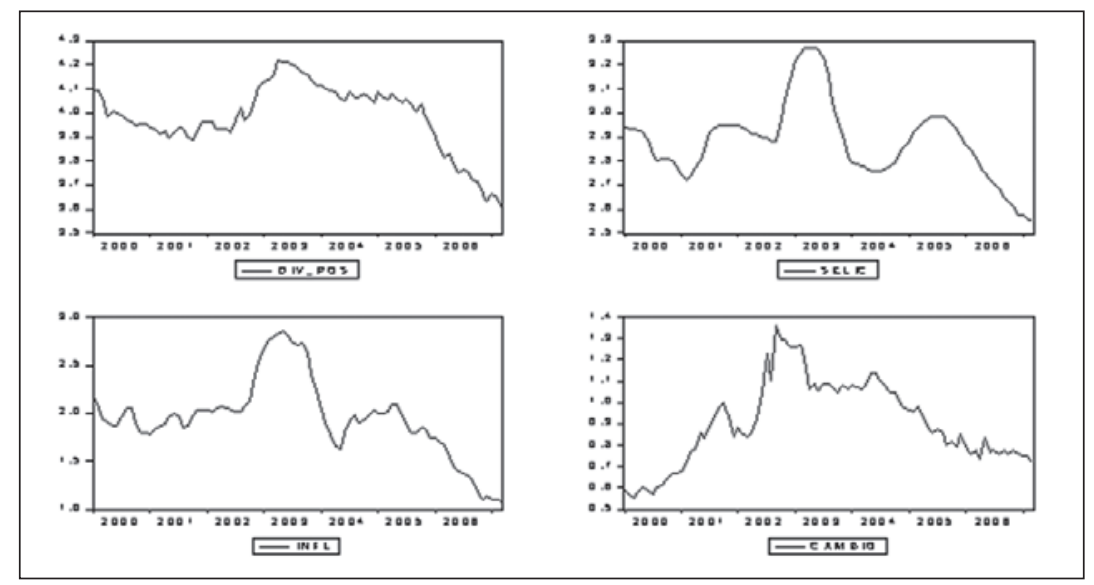

Figura 1 - Variáveis em Nível

Fonte: Elaborada pelos autores.

Tabela 1 - Teste ADF de Raiz Unitária

\begin{tabular}{c|c|c|c|c|c}
\hline Variáveis & Lags & Intercepto & Estatística $t$ & $\begin{array}{c}\text { Estatística t em } \\
1^{\text {a }} \text { diferença }\end{array}$ & Lags $1^{\text {a }}$ diferença \\
\hline Div_pos & 3 & $\operatorname{sim}$ & 0.2510 & $-3.8112^{*}$ & 2 \\
\hline Selic & 1 & $\operatorname{sim}$ & -2.7766 & $-2.9459^{*}$ & 0 \\
\hline Câmbio & 2 & $\operatorname{sim}$ & -1.6215 & -5.3074 & 1 \\
\hline Inflação & 1 & $\operatorname{sim}$ & -1.4231 & -4.3493 & 0 \\
\hline
\end{tabular}

*Rejeita hipótese nula de existência de raiz unitária ao nível de $1 \%$.

${ }^{1}$ Os testes em primeira diferença foram realizados sem intercepto, já que a hipótese alternativa passou a ser a de série estacionária em torno de uma média igual a zero.

Fonte: Elaborada pelos autores. 


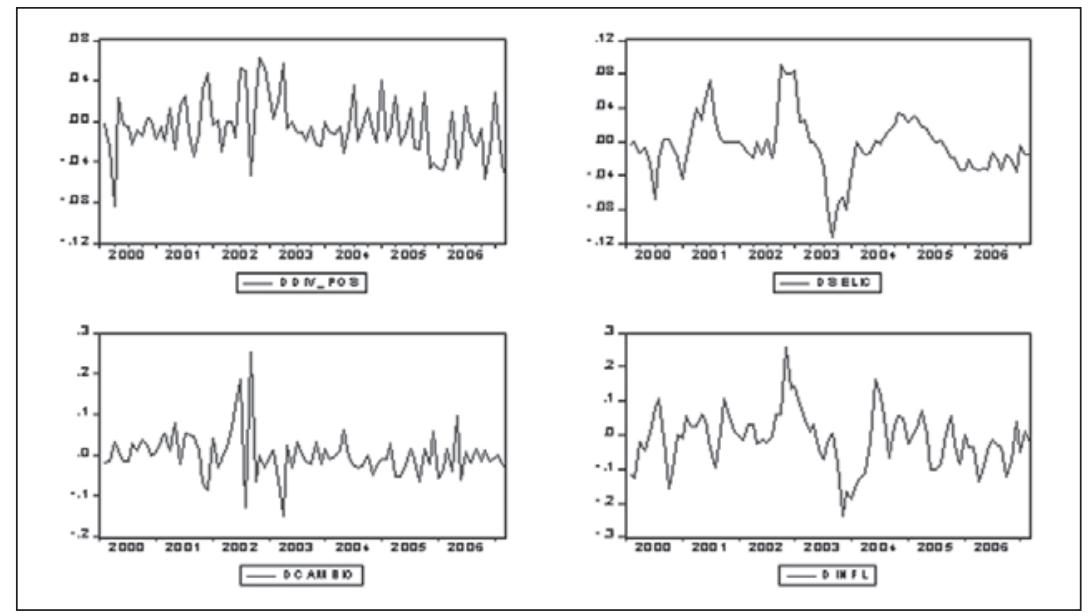

Figura 2 - Variáveis em $1^{\text {a }}$ Diferença i(1)

Fonte: Elaborada pelos autores.

Tabela 2 - Teste Jarque-Bera de Normalidade dos Resíduos

\begin{tabular}{c|c|c|c}
\hline Componente & Jarque-Bera & df & Prob. \\
\hline 1 & 7.470692 & 2 & 0.0239 \\
\hline 2 & 0.096388 & 2 & 0.9529 \\
\hline 3 & 5.387935 & 2 & 0.0676 \\
\hline 4 & 2.504767 & 2 & 0.2858 \\
\hline Conjunto & 15.45978 & 8 & 0.0508 \\
\hline
\end{tabular}

Fonte: Elaborada pelos autores. 
Tabela 3 - Teste LM de Correlação Serial

\begin{tabular}{c|c|c}
\hline Lags & LM-Stat & Prob. \\
\hline 1 & 20.0806 & 0.2166 \\
\hline 2 & 13.3669 & 0.6458 \\
\hline 3 & 23.8877 & 0.092 \\
\hline 4 & 18.7526 & 0.2817 \\
\hline 5 & 9.0656 & 0.9107 \\
\hline 6 & 12.2900 & 0.7238 \\
\hline 7 & 20.1151 & 0.2151 \\
\hline 8 & 15.3295 & 0.5007 \\
\hline 9 & 17.6543 & 0.3445 \\
\hline 10 & 18.7334 & 0.2827 \\
\hline 11 & 11.8413 & 0.7548 \\
\hline 12 & 20.3909 & 0.2031 \\
\hline
\end{tabular}

Fonte: Elaborada pelos autores.

Tabela 4 - Teste White de Heterocedasticidade

\begin{tabular}{c|c|c}
\hline Chi-sq & df & Prob. \\
\hline 273.741 & 240 & 0.0664 \\
\hline
\end{tabular}

Fonte: Elaborada pelos autores.

Tabela 5 - Teste Granger/Wald de Exogeneidade

\begin{tabular}{c|c}
\hline Variáveis & $\chi^{2}$ \\
\hline Câmbio & 13.72495 \\
\hline Selic & 25.35184 \\
\hline Inflação & 34.12207 \\
\hline Div_pos & 64.23663 \\
\hline
\end{tabular}

Fonte: Elaborada pelos autores. 


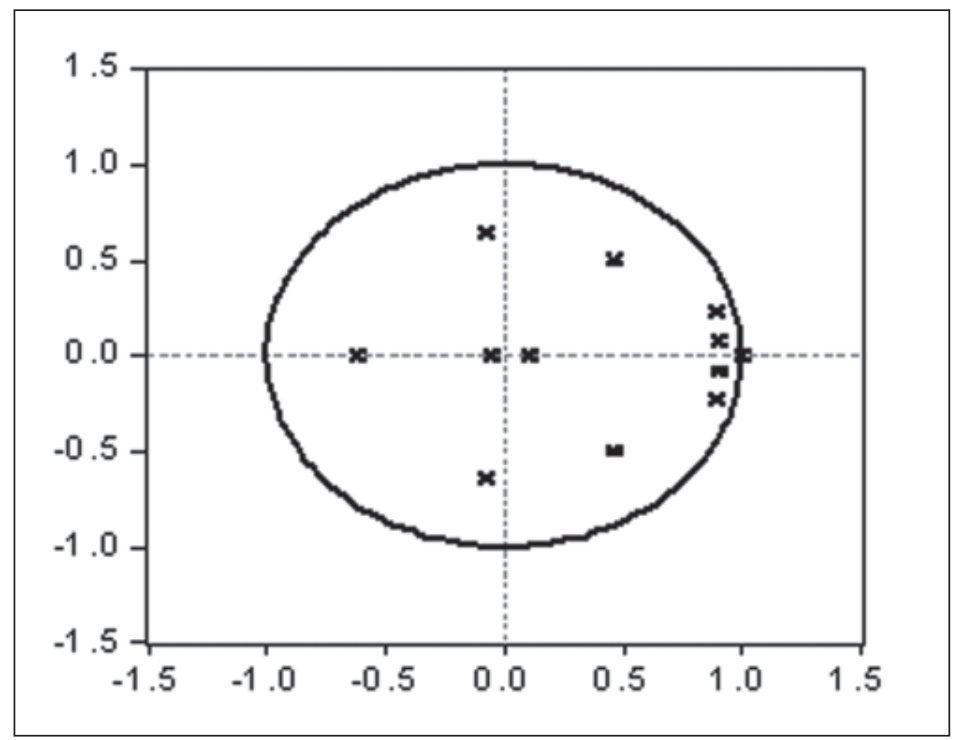

Figura 3 - Teste de Estabilidade do VAR - Raiz Inversa do Polinômio Característico Autorregressivo

Fonte: Elaborada pelos autores.

Tabela 6 - Teste de Cointegração de Johansen

\begin{tabular}{c|c|c|c|c}
\hline $\begin{array}{c}\text { Hipótese nula } \\
\text { de cointegração }\end{array}$ & Eigenvalue & LR trace & Valor crítico a 5\% & Valor crítico a 1\% \\
\hline None** & $\mathbf{0 . 2 6 7 1}$ & $\mathbf{5 4 . 5 7 4 0}$ & $\mathbf{4 7 . 2 1 0 0}$ & $\mathbf{5 4 . 4 6 0 0}$ \\
\hline At most 1 & 0.2123 & 28.7854 & 29.6800 & 35.6500 \\
\hline At most 2 & 0.1022 & 8.9818 & 15.4100 & 20.0400 \\
\hline At most 3 & 0.0005 & 0.0379 & 3.7600 & 6.6500 \\
\hline **Denota rejeição da hipótese nula ao nível de 5\%. \\
\hline $\begin{array}{c}\text { Hipótese nula } \\
\text { de cointegração }\end{array}$ & Eigenvalue & Máximo & Valor crítico a 5\% & Valor crítico a 1\% \\
\hline \multicolumn{7}{|c|}{ None*** } & $\mathbf{0 . 2 6 7 0 7 1}$ & $\mathbf{2 5 . 7 8 8 6 4}$ & $\mathbf{2 7 . 0 7}$ & $\mathbf{3 2 . 2 4}$ \\
\hline \multicolumn{7}{|c|}{ At most 1 } & 0.212268 & 19.80356 & 20.97 & 25.52 \\
\hline At most 2 & 0.102155 & 8.943921 & 14.07 & 18.63 \\
\hline \multicolumn{7}{|c|}{ At most 3 } & 0.000457 & 0.037906 & 3.76 & 6.65 \\
\hline$* *$ Denota rejeição da hipótese nula ao nível de 10\%.
\end{tabular}

Fonte: Elaborada pelos autores. 


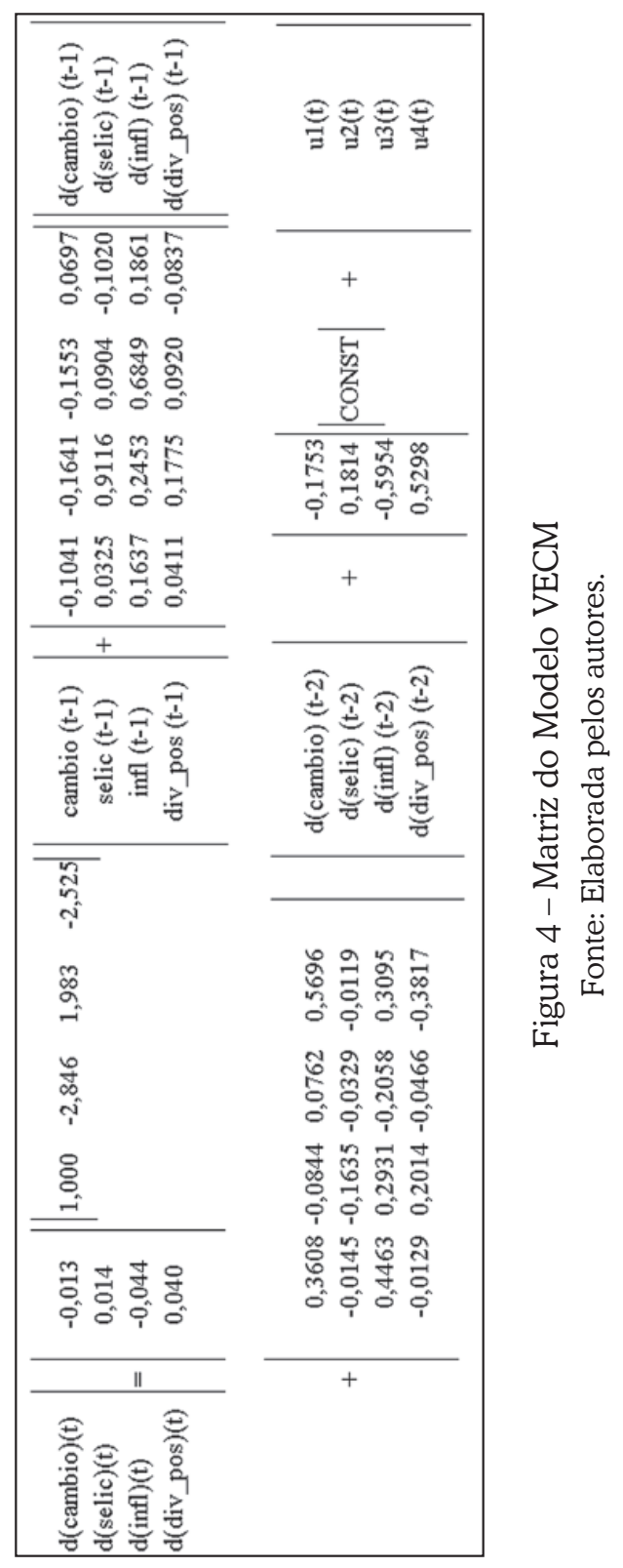




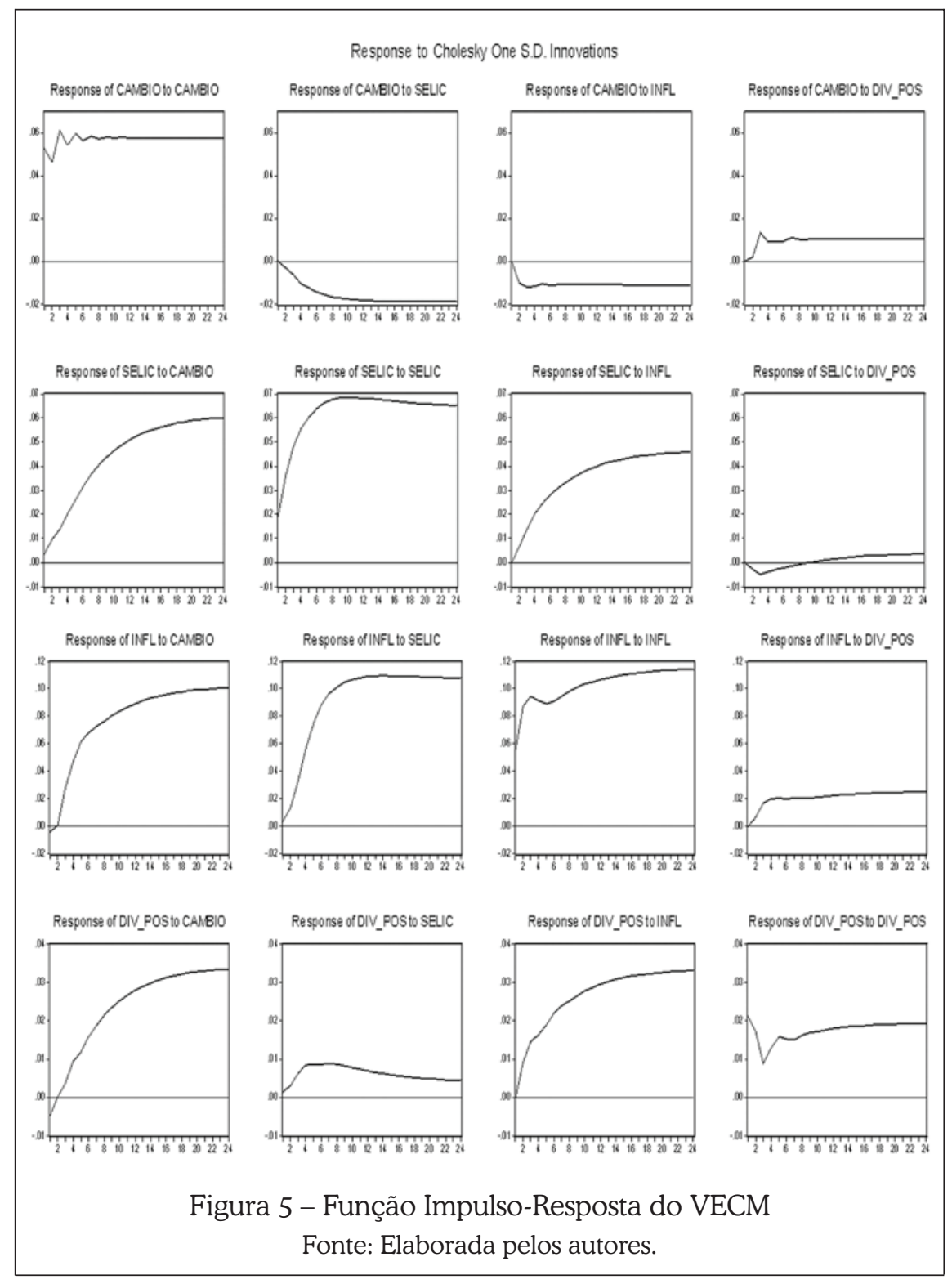


Tabela 7 - Decomposição da Variância da Variável Div_pos

\begin{tabular}{|c|c|c|c|c|c|}
\hline Período & S.E. & Câmbio & Selic & INFL & Div_pos \\
\hline 1 & 0.0215 & 4.7107 & 0.3738 & 0.0317 & 94.8837 \\
\hline 2 & 0.0291 & 2.5783 & 1.2091 & 9.7211 & 86.4915 \\
\hline 3 & 0.0344 & 2.9601 & 4.2088 & 24.5990 & 68.2322 \\
\hline 4 & 0.0420 & 6.7375 & 6.8930 & 31.4187 & 54.9508 \\
\hline 5 & 0.0508 & 10.1152 & 7.5585 & 35.1670 & 47.1594 \\
\hline 6 & 0.0602 & 14.1102 & 7.4585 & 38.4068 & 40.0246 \\
\hline 7 & 0.0695 & 17.7899 & 7.1805 & 40.4254 & 34.6042 \\
\hline 8 & 0.0791 & 21.0420 & 6.7265 & 41.2681 & 30.9633 \\
\hline 9 & 0.0886 & 23.6737 & 6.2028 & 41.8094 & 28.3142 \\
\hline 10 & 0.0980 & 25.9347 & 5.6921 & 42.1879 & 26.1853 \\
\hline 11 & 0.1072 & 27.8369 & 5.2252 & 42.4108 & 24.5271 \\
\hline 12 & 0.1162 & 29.4471 & 4.8013 & 42.5144 & 23.2372 \\
\hline 13 & 0.1249 & 30.8084 & 4.4235 & 42.5741 & 22.1940 \\
\hline 14 & 0.1334 & 31.9786 & 4.0904 & 42.6000 & 21.3310 \\
\hline 15 & 0.1417 & 32.9846 & 3.7976 & 42.6010 & 20.6169 \\
\hline 16 & 0.1497 & 33.8552 & 3.5397 & 42.5859 & 20.0192 \\
\hline 17 & 0.1575 & 34.6122 & 3.3126 & 42.5639 & 19.5112 \\
\hline 18 & 0.1651 & 35.2753 & 3.1121 & 42.5370 & 19.0755 \\
\hline 19 & 0.1725 & 35.8585 & 2.9347 & 42.5073 & 18.6996 \\
\hline 20 & 0.1796 & 36.3740 & 2.7770 & 42.4766 & 18.3724 \\
\hline 21 & 0.1866 & 36.8318 & 2.6364 & 42.4462 & 18.0856 \\
\hline 22 & 0.1933 & 37.2404 & 2.5107 & 42.4164 & 17.8325 \\
\hline 23 & 0.1999 & 37.6063 & 2.3978 & 42.3878 & 17.6081 \\
\hline 24 & 0.2063 & 37.9356 & 2.2961 & 42.3605 & 17.4079 \\
\hline
\end{tabular}

Fonte: Elaborada pelos autores. 
Tabela 8 - Decomposição da Variância da Variável Selic

\begin{tabular}{|c|c|c|c|c|c|}
\hline Período & S.E. & Câmbio & Selic & INFL & Div_pos \\
\hline 1 & 0.0196 & 3.8058 & 96.1942 & 0.0000 & 0.0000 \\
\hline 2 & 0.0429 & 5.9968 & 91.2675 & 2.2916 & 0.4440 \\
\hline 3 & 0.0674 & 6.7124 & 87.3630 & 5.2027 & 0.7219 \\
\hline 4 & 0.0918 & 8.4285 & 83.4608 & 7.5418 & 0.5690 \\
\hline 5 & 0.1156 & 10.3120 & 79.9946 & 9.2716 & 0.4217 \\
\hline 6 & 0.1388 & 12.3813 & 76.7810 & 10.5188 & 0.3189 \\
\hline 7 & 0.1611 & 14.3127 & 73.9831 & 11.4575 & 0.2467 \\
\hline 8 & 0.1824 & 16.0935 & 71.4741 & 12.2382 & 0.1943 \\
\hline 9 & 0.2027 & 17.6828 & 69.2193 & 12.9406 & 0.1573 \\
\hline 10 & 0.2222 & 19.1221 & 67.1671 & 13.5795 & 0.1313 \\
\hline 11 & 0.2407 & 20.4209 & 65.3076 & 14.1583 & 0.1132 \\
\hline 12 & 0.2585 & 21.5996 & 63.6183 & 14.6811 & 0.1009 \\
\hline 13 & 0.2755 & 22.6667 & 62.0865 & 15.1539 & 0.0929 \\
\hline 14 & 0.2918 & 23.6344 & 60.6965 & 15.5812 & 0.0880 \\
\hline 15 & 0.3075 & 24.5110 & 59.4357 & 15.9680 & 0.0853 \\
\hline 16 & 0.3227 & 25.3062 & 58.2907 & 16.3188 & 0.0842 \\
\hline 17 & 0.3373 & 26.0281 & 57.2502 & 16.6374 & 0.0843 \\
\hline 18 & 0.3514 & 26.6843 & 56.3035 & 16.9269 & 0.0853 \\
\hline 19 & 0.3651 & 27.2816 & 55.4412 & 17.1905 & 0.0867 \\
\hline 20 & 0.3784 & 27.8261 & 54.6544 & 17.4309 & 0.0886 \\
\hline 21 & 0.3913 & 28.3233 & 53.9357 & 17.6503 & 0.0907 \\
\hline 22 & 0.4038 & 28.7781 & 53.2779 & 17.8511 & 0.0929 \\
\hline 23 & 0.4159 & 29.1949 & 52.6750 & 18.0351 & 0.0951 \\
\hline 24 & 0.4278 & 29.5774 & 52.1213 & 18.2040 & 0.0974 \\
\hline
\end{tabular}

Fonte: Elaborada pelos autores.

Recebido em: 17/11/2008.

Aceito em: 20/12/2008. 